\title{
50. ANALYSIS OF DOWNHOLE LOGS, LEG 57, DEEP SEA DRILLING PROJECT
}

\author{
Takao Saki, Japan National Oil Corporation, Tokyo, Japan \\ Eiichi Honza, Geological Survey of Japan, Tsukuba, Japan \\ Roland von Huene, U. S. Geological Survey, Menlo Park, California \\ Noriyuki Nasu, Ocean Research Institute, University of Tokyo, Tokyo, Japan \\ and \\ Yasufumi Ishiwada, Japanese National Oil Corporation, Tokyo, Japan
}

\section{INTRODUCTION}

All sites drilled on Leg 57 were logged as weather conditions permitted. The logging was done by the Singapore office of Schlumberger, and because of short notice the special logging tools required to pass through the Challenger drill pipe were not available. The standard centralizer, excentralizer, and caliper tools were not appropriate, and those modified aboard ship were not completely satisfactory. In addition, we suspected that vertical motion from the ship's heave degraded the quality of logs. Both the sonic and neutron density tools were operated beyond their normal working ranges. Despite these operational difficulties, the logs from different runs in a hole, both repeat sections and runs with different tools, show generally the same features. Over intervals of 5 to 10 meters the field logs seem to be good indicators of the physical character of the section penetrated (Carson and Bruns, this volume).

The recovery of continuous core as well as logs differs from normal industrial drilling practice, in which a major purpose of logging is to establish lithology. Since lithology is best established by direct examination, the log analysis focused less on identifying a specific lithology than on continuous measurement of in situ physical properties, especially at Sites 438,439 , and 440 , where recovery was good. However, the logs were used to establish the lithology of missing intervals, especially at Site 441 , where recovery was poor. Lithology and physical properties aspects of the log analysis are covered in the individual site chapters and in a comparative analysis of laboratory measurements of physical properties and logged physical parameters (Carson and Bruns, this volume). In the present chapter we concentrate on log precision, correlation of key horizons in seismic records and core lithology, and on fracturing as indicated by the logs. We do this by using the results of a study of corrected logs and the derivative products from computer programs developed by the Scientific Software Corporation (SSC) and Technology Research Center and of corrected logs from Schlumberger (available from DSDP).

\section{DATA ANALYSIS PROGRAM}

The analytical programs developed by the SSC and TRC, JNOC were used to make the following calculations (see Table 1 for abbreviation of log names and parameters):
1) Correction of bulk density log (RHOB) for a measured or an assumed change in borehole diameter. (RHOC)

2) Correction of gamma ray log (GR) for changes of borehole diameter and for corrections of mud water and water density (when possible, the hole was filled with mud for logging). (GRCO)

3) Calculation of porosity from the sonic (PHIS) and the formation density (PHID) logs and calculation of the sonic compaction factor (CP).

4) Calculation of velocity (VEL) from the sonic log.

5) Calculation of cross plots.

6) Check of time-depth relationships and calculation of synthetic seismograms.

The analog log traces produced on the ship were first digitized manually at 2-mm intervals on the trace, which is equal to $40 \mathrm{~cm}$ in the hole, and a digital tape compiled in a format compatible with the SSC program. During compilation some noise was rejected and the data resampled at an interval equivalent to 1 meter in the hole. The tape was then run with the SSC program. The input and output are given in Table 1, although not all output products are presented.

The borehole compensated sonic (DLT), corrected formation density (RHOC), and compensated neutron porosity (PHIN) were used to calculate porosities.

Porosity from sonic data in the clean sandstone $\left(\phi_{\mathrm{ss}}\right)$ was calculated using the Wyllie time-average equation (Wyllie et al., 1956, 1958)

$$
\phi_{s s}=\frac{\Delta_{t}-\Delta_{t m a}}{\Delta_{t f}-\Delta_{t m a}},
$$

where $\Delta_{t}$ is a reading of the sonic log, $\Delta_{t m a}$ is sonic transit time of the formation matrix, and $\Delta_{t f}$ is sonic transit time in the sea water. When the shaly (muddy) material is contained, the equation becomes

$$
\phi_{s}=\phi_{s s}+V_{s h} \frac{\Delta_{t s h}-\Delta_{t m a}}{\Delta_{t f}-\Delta_{t m a}},
$$

where $\phi_{s}$ is sonic porosity, $V_{s h}$ is shale fraction, and $\Delta_{t s h}$ is sonic transit time of the shale.

We considered zero for $\phi_{s s}$ and 1 for $V_{s h}$, since most of the section drilled was mud or mudstone, which resulted in use of the upper, simple equation. We used $205 \mu \mathrm{s} / \mathrm{ft}$. $(1.49 \mathrm{~km} / \mathrm{s})$ for $\Delta_{t f}$ and $55.5 \mu \mathrm{s} / \mathrm{ft}$. (5.49 $\mathrm{km} / \mathrm{s}$ ) for $\Delta_{\text {Ima }}$ in the analysis. Direct application of the 
TABLE 1

Logging Data, Site 438-441

Logging Data

\begin{tabular}{lll} 
Abbreviation & \multicolumn{1}{c}{ Term } & \multicolumn{1}{c}{ Unit } \\
\hline DLT $(\Delta \mathrm{T})$ & Borehole Compensated Sonic & $\mu$ sec/ft \\
RHOB $(\rho \mathrm{b})$ & Formation Density & $\mathrm{g} / \mathrm{cc}$ \\
RHOC $(\rho \mathrm{c})$ & Corrected RHOB & $\mathrm{g} / \mathrm{cc}$ \\
GR & Gamma Ray & API unit \\
GRCO & Corrected GR & API unit \\
PHIN $(\phi \mathrm{n})$ & Neutron Porosity & $\%$ \\
TEMP & Temperature & ${ }^{\circ} \mathrm{C}$ \\
CAL & Caliper & inch \\
RLLD & Dual Laterolog Deep & $\Omega-\mathrm{m}$ \\
VEL & Velocity from Sonic & $\mathrm{km} / \mathrm{s}$ \\
PHID $(\phi \mathrm{d})$ & Porosity from Density & $\%$ \\
PHIS $(\phi \mathrm{s})$ & Porosity from Sonic & $\%$ \\
CP & Compaction Factor & \\
MPLT & M-N Plot & \\
NPLT & & \\
\hline
\end{tabular}

Input Data and Logging Interval (m)

\begin{tabular}{lcccc} 
& Hole 438A & Hole 439 & Hole 440B & Hole 441A \\
\hline $\begin{array}{lcccc}\text { Water } \\
\text { Depth (m) }\end{array}$ & 1558 & 1666 & 4507 & 5646 \\
GR & $1675-2400$ & $1765-2600$ & $4625-5249$ & $5763-6223$ \\
RLLD & $1675-2420$ & $1850-2600$ & - & - \\
CAL & - & - & $4627-5249$ & - \\
RHOB & $1675-2420$ & $1765-2620$ & $4625-5274$ & $5763-6223$ \\
DLT & $1675-2420$ & $1775-2750$ & $4625-5249$ & - \\
PHIN & $1675-2424$ & $1765-2600$ & $4624-5275$ & - \\
TEMP & $1500-2430$ & $1600-2600$ & $4510-5004$ & - \\
\hline
\end{tabular}

Output

Hole 438A Hole 439 Hole 440B Hole 441A

\begin{tabular}{lllll}
\hline GRCO & $\mathrm{a}$ & $\mathrm{a}$ & $\mathrm{a}$ & $\mathrm{a}$ \\
RLLD & $\mathrm{a}$ & $\mathrm{a}$ & $-\mathrm{b}$ & $-\mathrm{b}$ \\
CAL & $-\mathrm{b}$ & $-\mathrm{b}$ & $\mathrm{a}$ & $-\mathrm{b}$ \\
RHOC & $\mathrm{a}$ & $\mathrm{a}$ & $\mathrm{a}$ & $\mathrm{a}$ \\
DLT & $\mathrm{a}$ & $\mathrm{a}$ & $\mathrm{a}$ & $-\mathrm{b}$ \\
PHIN & $\mathrm{a}$ & $\mathrm{a}$ & $\mathrm{a}$ & $-\mathrm{b}$ \\
TEMP & $\mathrm{a}$ & $\mathrm{a}$ & $\mathrm{a}$ & $-\mathrm{b}$ \\
PHIS & $\mathrm{a}$ & $\mathrm{a}$ & $\mathrm{a}$ & $-\mathrm{b}$ \\
PHID & $\mathrm{a}$ & $\mathrm{a}$ & $\mathrm{a}$ & $-\mathrm{b}$ \\
CP & $\mathrm{a}$ & $\mathrm{a}$ & $\mathrm{a}$ & $-\mathrm{b}$ \\
VEL & $\mathrm{a}$ & $\mathrm{a}$ & $\mathrm{a}$ & $-\mathrm{b}$ \\
M-N & $\mathrm{c}$ & $\mathrm{c}$ & $\mathrm{c}$ & $-\mathrm{b}$ \\
LITH- & $\mathrm{d}$ & $\mathrm{d}$ & $\mathrm{d}$ & $\mathrm{c}$ \\
OLOGY & & & & \\
SEISMO- & $\mathrm{d}$ & $\mathrm{d}$ & $\mathrm{d}$ & $-\mathrm{b}$ \\
GRAM & & & &
\end{tabular}

${ }_{b}^{a}$ Plot and List.

- = no data.

c List.

dPlot.

A verage Geothermal Gradient (uncorrected, ${ }^{\circ} \mathrm{C} / 100 \mathrm{~m}$ )

\begin{tabular}{lccc} 
& Hole 438A & Hole 439 & Hole 440B \\
\hline $1600-2400$ & 2.95 & & \\
$1750-2550$ & & 2.64 & 1.41 \\
$4550-2950$ & & & \\
\hline
\end{tabular}

Wyllie equation gives values of porosity which are too high in unconsolidated and insufficiently compacted layers. Such lack of compaction may be present in shales exhibiting $\Delta_{t}$ values greater than $100 \mu \mathrm{s} / \mathrm{ft}$. When formations are not sufficiently compacted, the observed $\Delta$, values are greater than $100 \mu \mathrm{s} / \mathrm{ft}$., which would correspond to the porosity according to the Wyllie equation. An empirical compaction factor $\mathrm{CP}$ is applied to the Wyllie equation to give a corrected porosity $\left(\phi_{s c}\right)$ :

$$
\phi_{s c}=\frac{\Delta_{t}-\Delta_{t m a}}{\Delta_{l f}-\Delta_{t m a}} \cdot \frac{1}{\mathrm{CP}} .
$$

The values of $\mathrm{CP}$ are best determined by comparing $\phi_{s}$ with the true porosity. Because we used $\phi_{d}$ (porosity from the density log) instead of true porosity, the compaction factor $(\mathrm{CP})$ is expressed as follows,

$$
\mathrm{CP}=\phi_{s} / \phi_{d} .
$$

Porosity calculation from the formation density log $\left(\phi_{d}\right)$ is similar to that from the sonic log,

$$
\phi_{d}=\phi_{d s}+V_{s h} \frac{\varrho_{m a}-\varrho_{s h}}{\varrho_{m a}-\varrho_{f}},
$$

where $\phi_{d s}$ is clean sandstone porosity ( $\left.=0\right), V_{s h}$ is shale fraction (=1), $\varrho_{m a}$ is formation matrix density (= 2.65), $\varrho_{f}$ is formation water density $(=1.0)$, and $\varrho_{s h}$ is a reading from the log.

The porosity calculated from the density log is sensitive to total porosity (including vuggy and/or fracture porosity); the porosity calculated from the sonic log cannot detect vuggy and/or fracture porosity but is sensitive largely to intergranular porosity.

The secondary porosity index (SPI) may be computed as the difference between total porosity as determined from the neutron and/or density $\log (\phi)$ and a corrected porosity from the sonic log results, using the following equation:

$$
\mathrm{SPI}=\phi-\phi_{S c} .
$$

Neutron porosity logs respond primarily to the amount of hydrogen present in the formation. In a "clean formation" whose pores are filled with water the neutron logs indicate directly the amount of water-filled porosity. When the shaly (muddy) materials are present, values of $\left(\phi_{n}\right)$ are obtained by

$$
\phi_{n}=\phi+V_{s h} \cdot \phi_{n s h},
$$

where $\phi$ is true porosity (clean sand porosity) and $\phi_{n s h}$ is the logged value when $V_{s h}$ (shale fraction) equals 1 . The value of $\phi_{n s h}$ depends on the type of shale, the compaction, and the type of tool.

On Leg 57 , the formation was essentially mud or mudstone, and although the neutron log was not useful in estimating the formation porosity, it did indicate a compaction effect. 
Other calculations, such as crossplots of DLT/RHOB and $\mathrm{M}-\mathrm{N}$ plots, were made, but not all are shown here. The log-derived lithologies were compared with smear slide summaries.

Reflection coefficients for a given horizon $(R)$ were calculated from the sonic velocity $(V)$ and corrected bulk density $(\varrho)$ results using the following equation:

$$
R=\frac{V_{2} \varrho_{2}-V_{1} \varrho_{1}}{V_{2} \varrho_{2}+V_{1} \varrho_{1}},
$$

where $V_{1} \varrho_{1}$ is the acoustic impedance of the upper layer and $V_{2} \varrho_{2}$ is the impedance of the lower layer. Synthetic seismograms were constructed using the reflection coefficients by convolution of a $30-\mathrm{Hz}$ Ricker wavelet. The time-depth conversion was derived from a few points of time-depth calibration points and integration of the sonic log curves.

\section{DESCRIPTION OF LOG AND DERIVATIVE PLOTS}

The data input and derivative output are summarized in Table 1. Certain operational problems that affect the logs should be noted. Only one caliper log was obtained (Site 440). This log indicates general enlargement of the upper parts of the hole. In addition it shows abrupt hole diameter changes, usually of 1 inch and sometimes of 3 inches. Hole diameter varies between about 11 (bit size) and 15.5 inches (28 and $40 \mathrm{~cm}$ ). This is considered a rough hole for logging, particularly if the springs that hold a tool against the side of the hole are weak. Thus these logs were significantly affected by contact between the tool and the side of the hole and by hole diameter. Abrupt washout cannot be strictly correlated with lithology, because drilling fluid (sea water) was circulated for about 20 minutes at positions about 9.5 meters apart during "pump down" of a core barrel, thus exposing various intervals to greater than normal circulation. In the holes where the correction for hole diameter was assumed but not measured $(438,439$, and 441), there may be an effect from uncompensated washout; however, such an effect is not apparent from the $\log$ interpretations for Sites 438, 439, and 441 (Figures 1-3).

The sonic log showed signs of cycle-skipping that appeared obvious in the field prints. Cycle-skipping generally occurs when the sonic signal is strongly attenuated by unconsolidated formations, formation fracture, and gas saturation, causing a very abrupt and large excursion toward higher DLT values. Perhaps some cycle-skipping occurred when the tool was not in contact with the hole. Most effects from cycle-skipping have been removed in the environmentally corrected logs shown in Figures 1 through 3). This is verified by comparing logged velocity and laboratory measurements of velocity on the core.

A description of the character of the logs from each site follows. We have grouped those from Sites 438 and 439.

\section{Sites 438 and 439}

The site chapter for Site 439 discusses the good correlation among all logs from 438 and 439 . The similarity of trends, the corresponding events in all the logs from a hole, and the good correlation between two holes $6 \mathrm{~km}$ apart argue for the general validity of the gamma ray, sonic, formation density, and temperature log data despite operational difficulties. The dual laterolog deep (RLLD) and neutron porosity log (PHIN) have less "character" than other logs, perhaps because of the uniform water-saturated muddy lithology. More character is apparent on large-scale printouts than on those in Figures 1 and 2.

The general character of a log trace corresponds well with lithology.

Sub-unit $2 \mathrm{~A}$, a homogenous unit, is characterized by a smooth curve and uniform values of bulk density and sonic velocity. Some spikes on the log curves are perhaps the response of a goup of thin volcanic ash layers.

Sub-unit 2B has heterogenous lithology because it marks the beginning of diagenetic changes and increased compaction; the corresponding log traces are considerably more variable. Generally, density and velocity curves increase with depth, but at the lower parts of Site 439 , there may be a slight decrease density curve with depth.

Sub-unit $2 \mathrm{C}$ consists of thicker units and numerous limestone layers; the corresponding traces show a short period variability superimposed on a long period wander. Sonic velocity generally increases with depth, but in the lower part of this unit, bulk density decreases with depth. At the boundary between Units 2 and 3, the pronounced change in lithology is marked by a pronounced shift in all the log traces. In Unit 3, both density and sonic velocity increase with depth. For greater detail, the reader is referred to the logs available at DSDP.

The in situ physical properties correspond generally to those measured on core analysis in the laboratory (Carson and Bruns, this volume). Sonic velocity at Site 438 ranges from 1.5 to $1.9 \mathrm{~km} / \mathrm{s}$ in Unit 2 and shows a general smooth increase with depth. Unit 2 is deeper at 439 and has a correspondingly higher range (1.5-2.2 $\mathrm{km} / \mathrm{s}$ ). Units 3 to 5 range from 2.1 to $2.8 \mathrm{~km} / \mathrm{s}$.

The laboratory-measured density values are systematically lower $\left(0.2-0.3 \mathrm{mg} / \mathrm{m}^{3}\right)$ than the formation density log values. We have no adequate explanation for this offset, but the two types of measurement reflect the same trend.

In the calculated porosity for both Sites 438 and 439 , the traces are separated by about 40 per cent at the upper end of the derivative plot and gradually converge at the lower end of the logging interval. The convergence with increasing depth may be caused by increasing compaction, which tends to minimize the calculated differences.

Cross plots of sonic transit time vs. formation density (DLT/RHOB), and M-N show some general trends of 

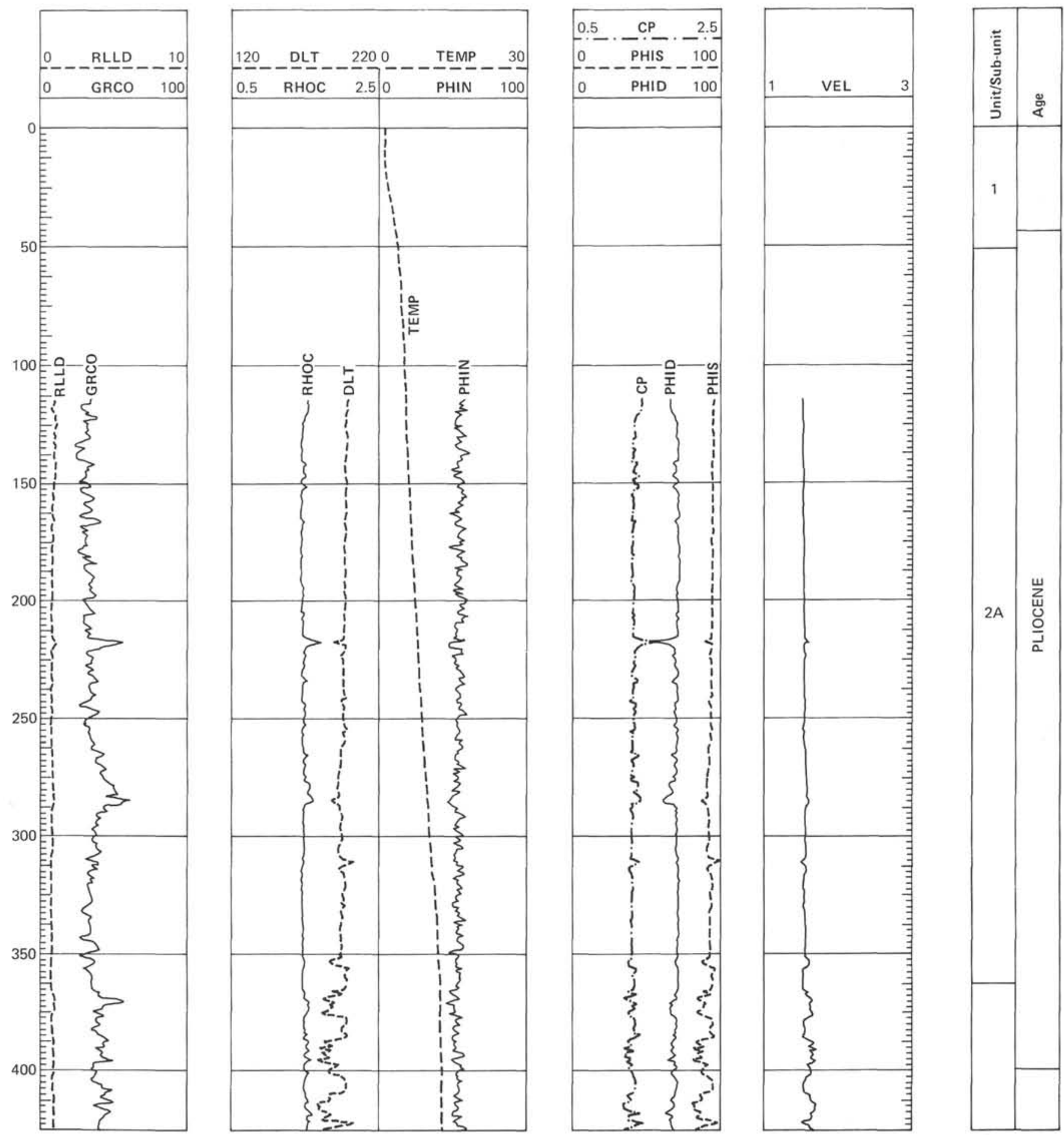

Figure 1. Logs from Site 438 (Hole 438A), corrected for environmental effects, and derivative porosity and velocity traces. $(R L L D=$ laterolog; $G R C O=$ gamma ray, corrected; $D L T=$ sonic; $R H O C=$ formation density, corrected $; T E M P=$ temperature $;$ PHIN = neutron porosity $; C P=$ compaction factor $; P H I S=$ porosity from sonic $\log ;$ PHID = porosity from density $\log ;$ VEL = velocity from sonic log.)

physical properties with depth and their combined values for lithologic units (Figures 4 and 5). The DLT/RHOB plots illustrate stepwise the increase of density with velocity over the logged interval. The scatter of points appears greatest in Sub-units $2 \mathrm{~B}$ and $2 \mathrm{C}$, in which initial diagenetic effects and increased consolida- tion are seen in the core. The relatively tight clustering of points over intervals more than 200 meters in thickness again suggests the general validity of the logging data. The M-N plot should reflect change in mineralogy independent of porosity. However, from core data, the grain density and mineralogy appear to remain relative- 

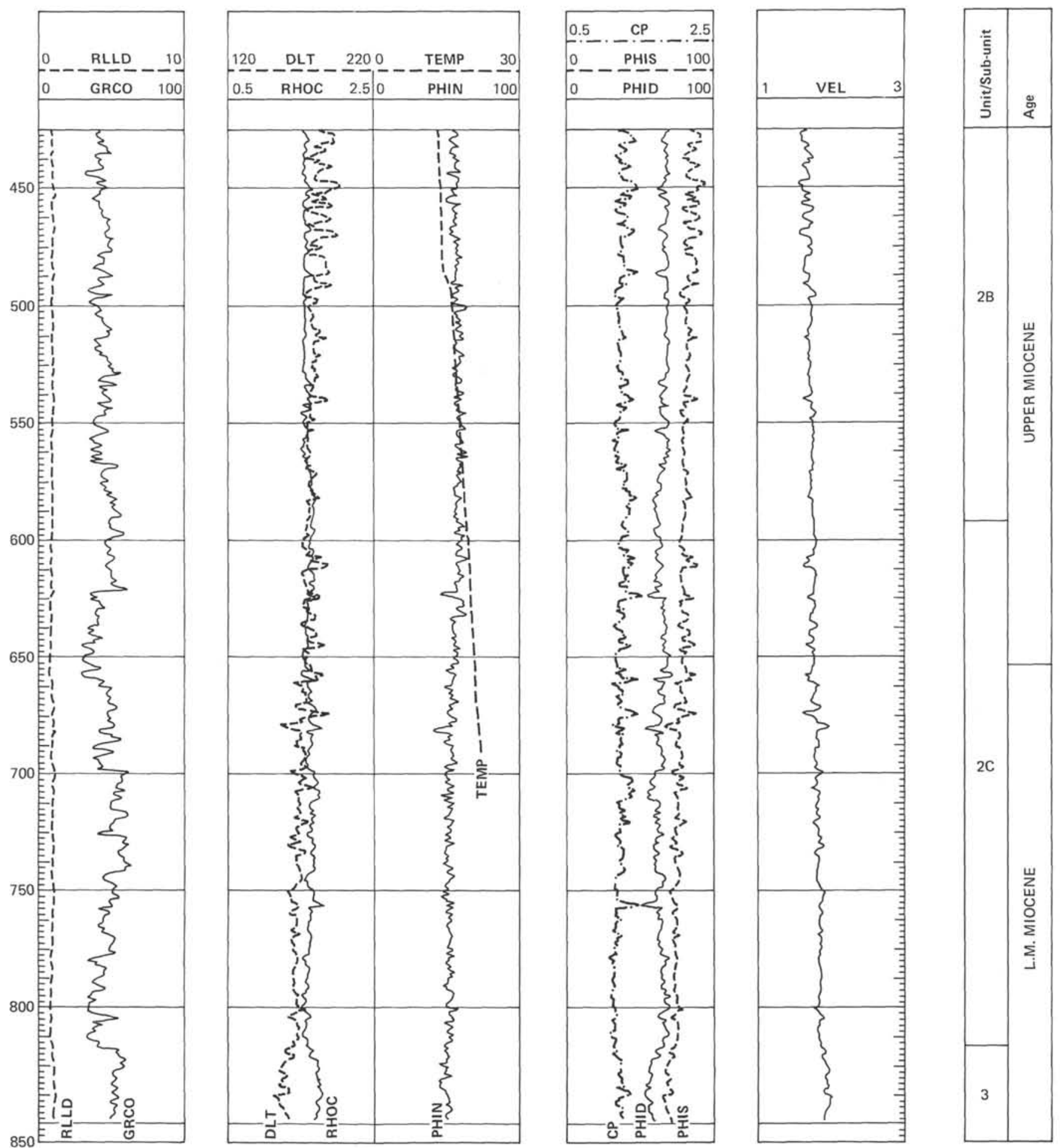

Figure 1. (Continued).

ly constant. Thus the shifts in $\mathrm{M}-\mathrm{N}$ plots for each unit must also reflect other changes.

\section{Site 440}

Because logging at Site 440 was done during stormy conditions, the large swells must have been superimposed on the logs to some degree as motion during the run. The suite of logs is responsive to physical changes that result from fracture, synsedimentary folding, and,

perhaps, secondary porosity. Considered together with the lithology of a well-recovered suite of core, the logs show important changes from the physical conditions at the top of the Japan Trench slope at Sites 438 and 439. The logs and the measurements of physical properties are in good agreement (Carson and Bruns, this volume).

The caliper log is a key log because it shows a large washout that affected the values (Figure 3 ). The hole appears relatively smooth but of oversized diameter 

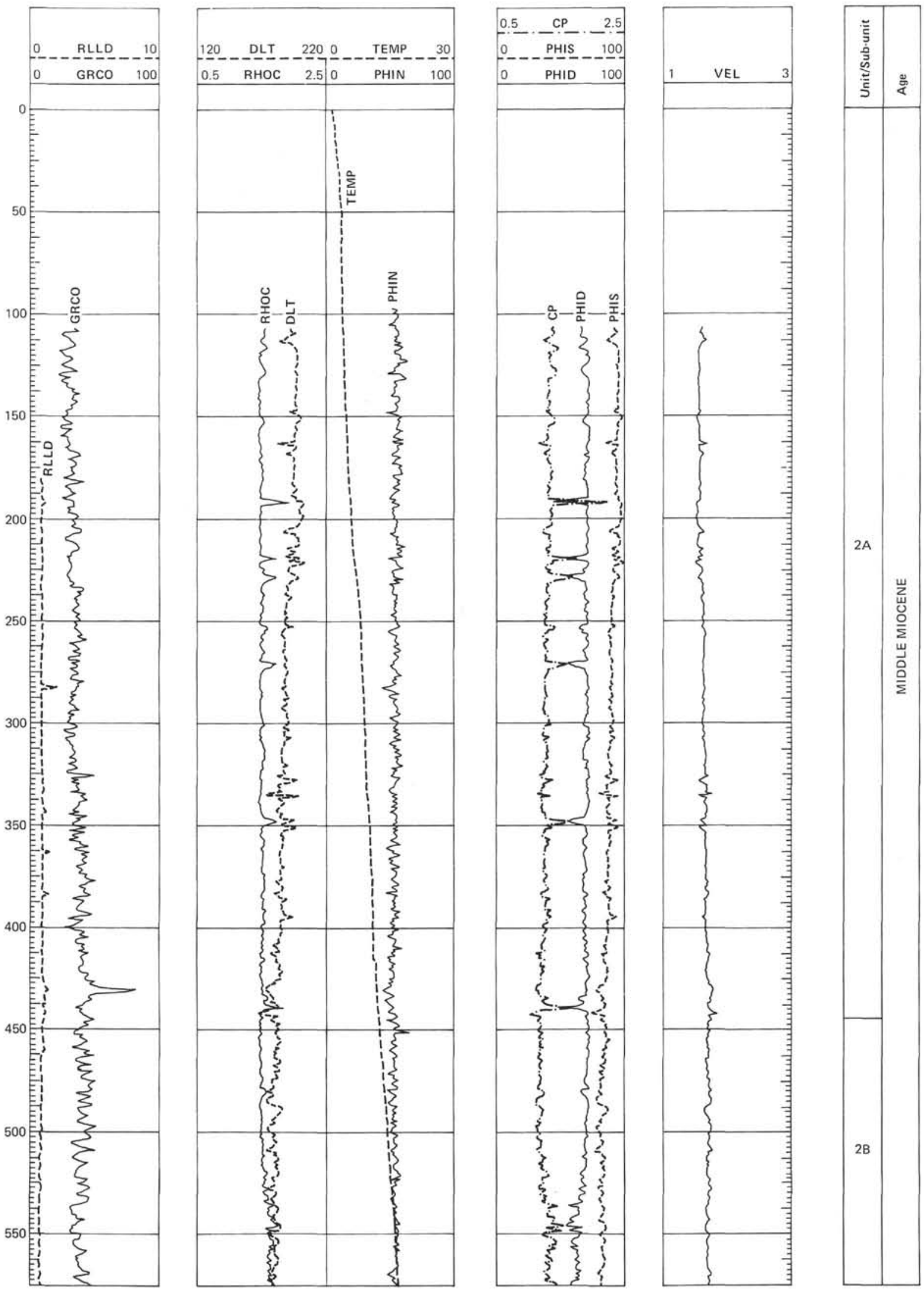

Figure 2. Logs from Site 439, corrected for environmental effects, and derivative porosity and velocity traces. $(R L L D=$ laterolog; $G R C O=$ gamma ray, corrected $D L T=$ sonic; $R H O C=$ formation density, corrected; TEMP = temperature; $P H I N=$ neutron porosity; $C P=$ compaction factor; $P H I S=$ porosity from sonic log; PHID = porosity from density log; VEL = velocity from sonic log.) 

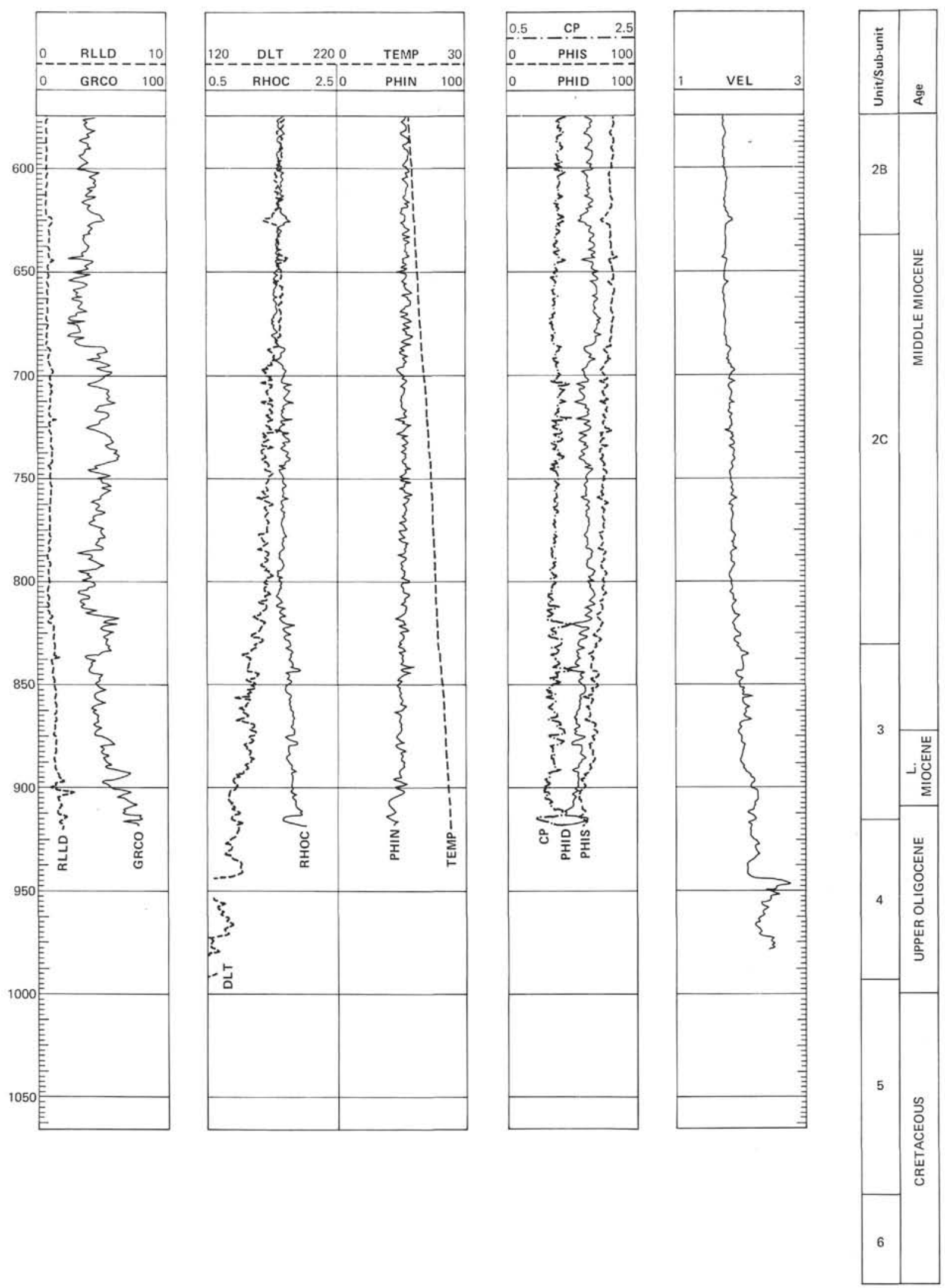

Figure 2. (Continued). 

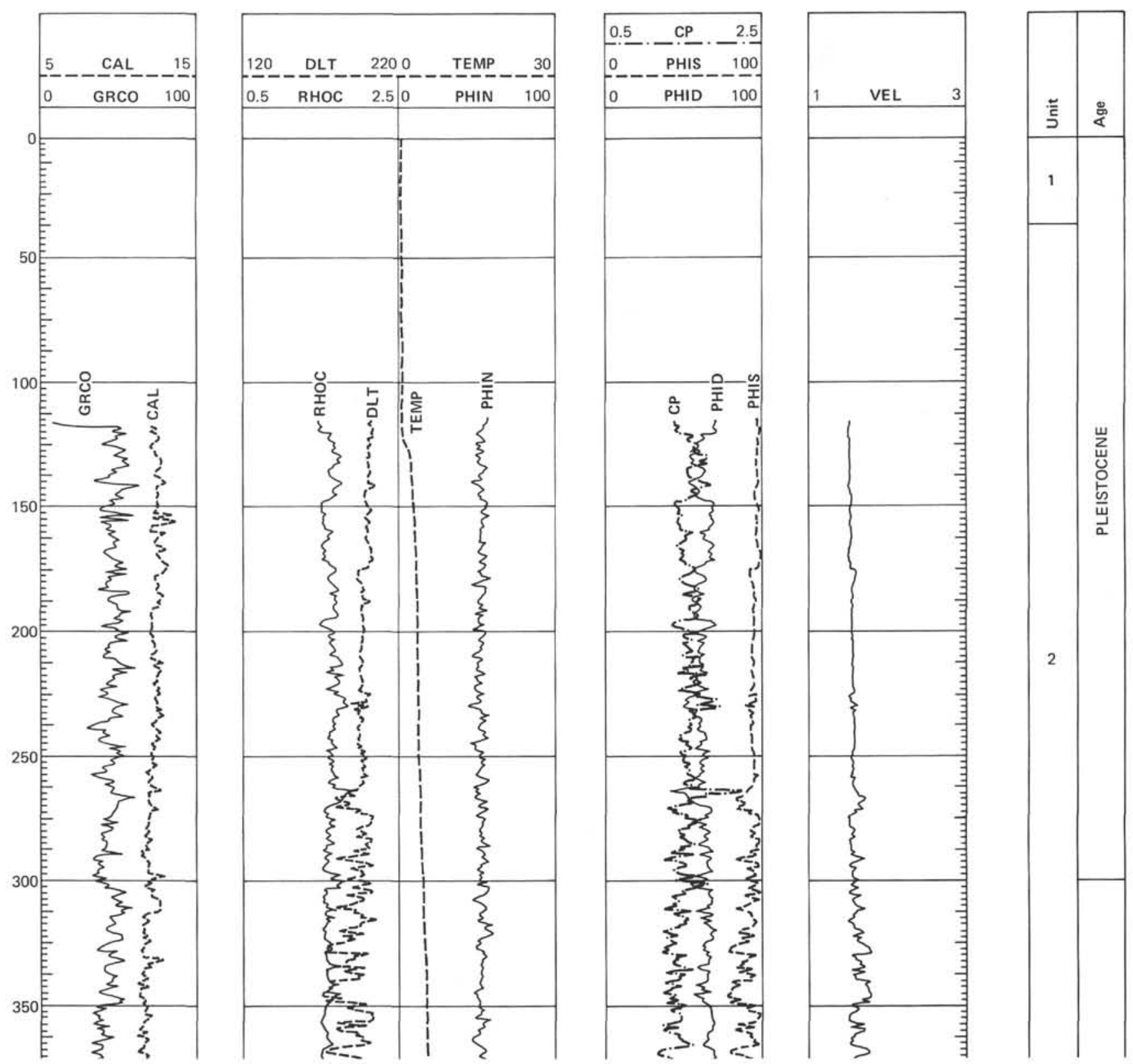

Figure 3. Logs from Site 440, corrected for environmental effects, and derivative porosity and velocity traces. (CAL = caliper; $G R C O=$ gamma ray, corrected; $D L T=$ sonic; $R H O C=$ formation density, corrected; TEMP = temperature; $P H I N=$ neutron porosity; $C P=$ compaction factor; $P H I S=$ porosity from sonic log; $P H I D=$ porosity from density log; VEL = velocity from sonic log.)

(100-290 m). From 100 to 200 meters the sonic and, less obviously, the formation traces are smooth except at local washouts. The latter is also the area where the sediment makes a transition from a plastic to a brittle state. A relatively rough area between 300 and 400 meters is followed by a relatively smooth area from 400 to about 565 meters. There are some large washouts below 560 meters. The relation between large washouts and "spikes" in the log traces is shown in Figure 3, except in the neutron porosity log. Commonly the washouts correspond to recovered sediment that is highly fractured or folded and to unrecovered intervals. Thus the logs indicate that fracturing is a cause for local poor recovery.
Sonic velocity increases steadily through the logged interval. However, between 260 and 300 meters the trace is unusually irregular. Cycle-skipping and spikes occurred often in this interval and not always at a washout section; this may be caused by vertical ship motion or fracturing. From 400 meters down, the trace is smooth, increasing gradually in roughness with depth. Cycleskip occurred at 500 to 510 meters. The character of the formation density log corresponds to the sonic log trace, but fluctuations are more subdued. The trends of the sonic and density trace coincide well in the interval between 400 meters and about 560 meters, which is a large part of the proposed geopressured interval (Carson and 

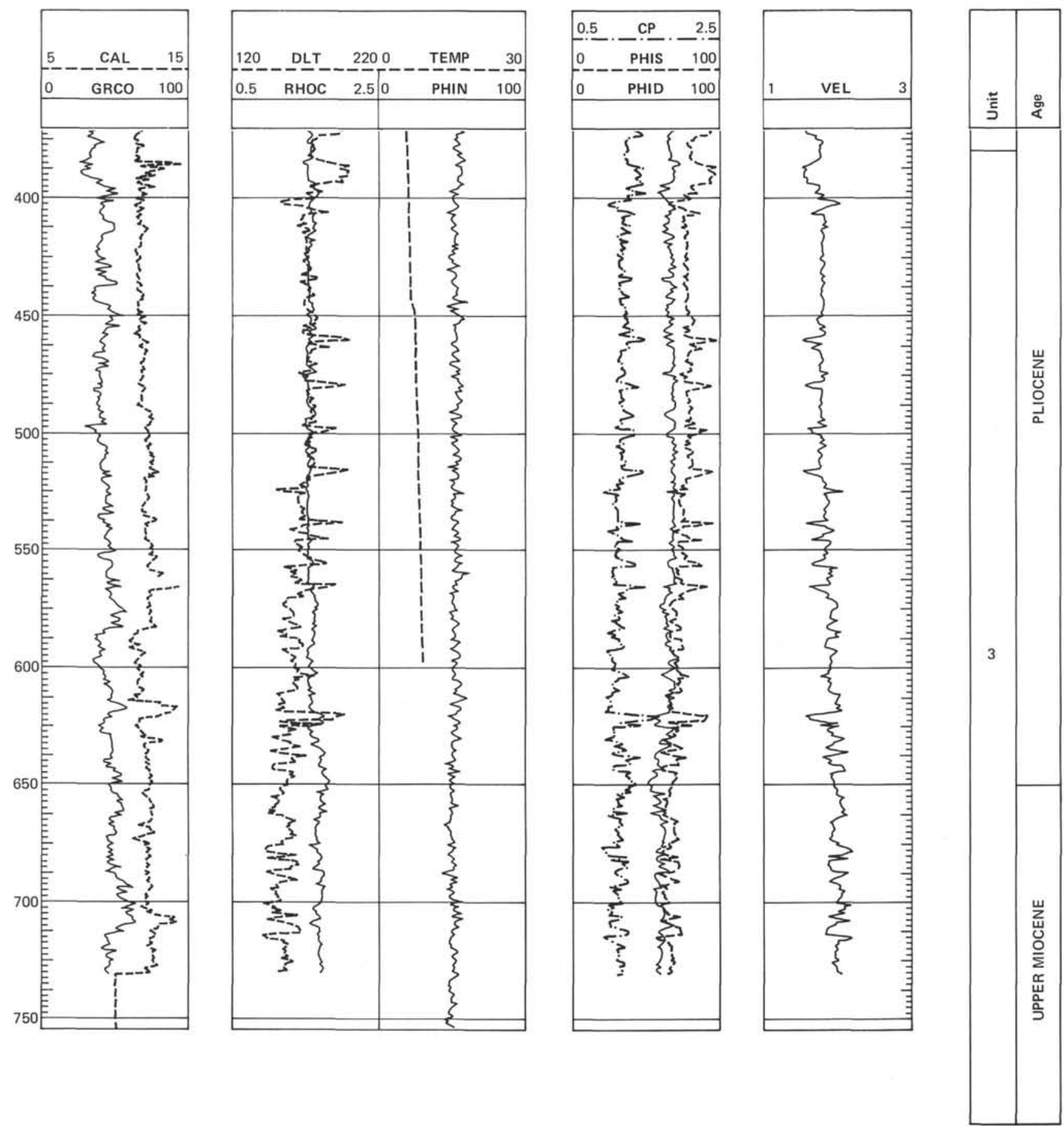

Figure 3. (Continued).

Bruns and Arthur et al., this volume). The decrease in density discussed by these authors is best seen in the CP trace (Figure 3) and on the full-scale logs, particularly at the scale of the field print.

It may be instructive to note that the values of the PHID trace increase to about 550 meters and only then begin to decrease, another supporting argument for the development of secondary porosity. The PHIS trace has an opposing trend to 400 meters, where both traces run parallel and at a nearly constant value to 560 meters and then slowly converge. The adjacent velocity shows a

similar interval of constant value between 400 and 560 meters as the sonic derivative porosity trace.

The unusual character of the interval between 400 and 560 meters is seen again in the cross plots (Figure 6). The DLT/RHOB plot of Sites 438 and 439 shows a shift of increasing density with increasing velocity in Units 2 and 3 ; at Site 440 density decreases with increasing velocity in the interval between 400 and 560 meters (upper part of Unit 3, Site 440). To see this clearly, one must isolate points with a DLT greater than 160 (corresponding to the DLT above 560 meters in Unit 3 ) on 
T. SAKIET AL.
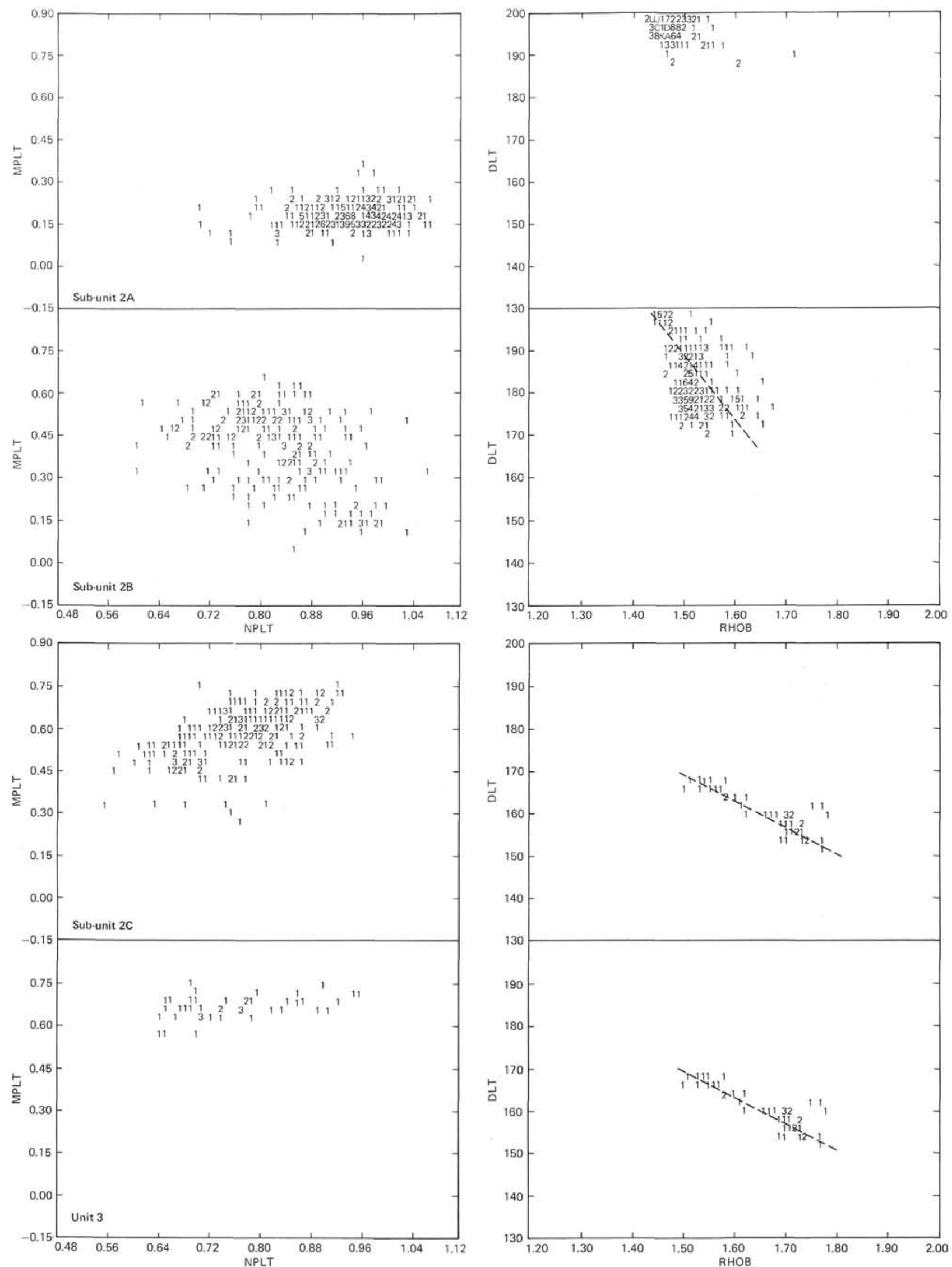

Figure 4. Cross plots of logs from Site 438. (M-N plots on right, DLT/RHOB on left.) 

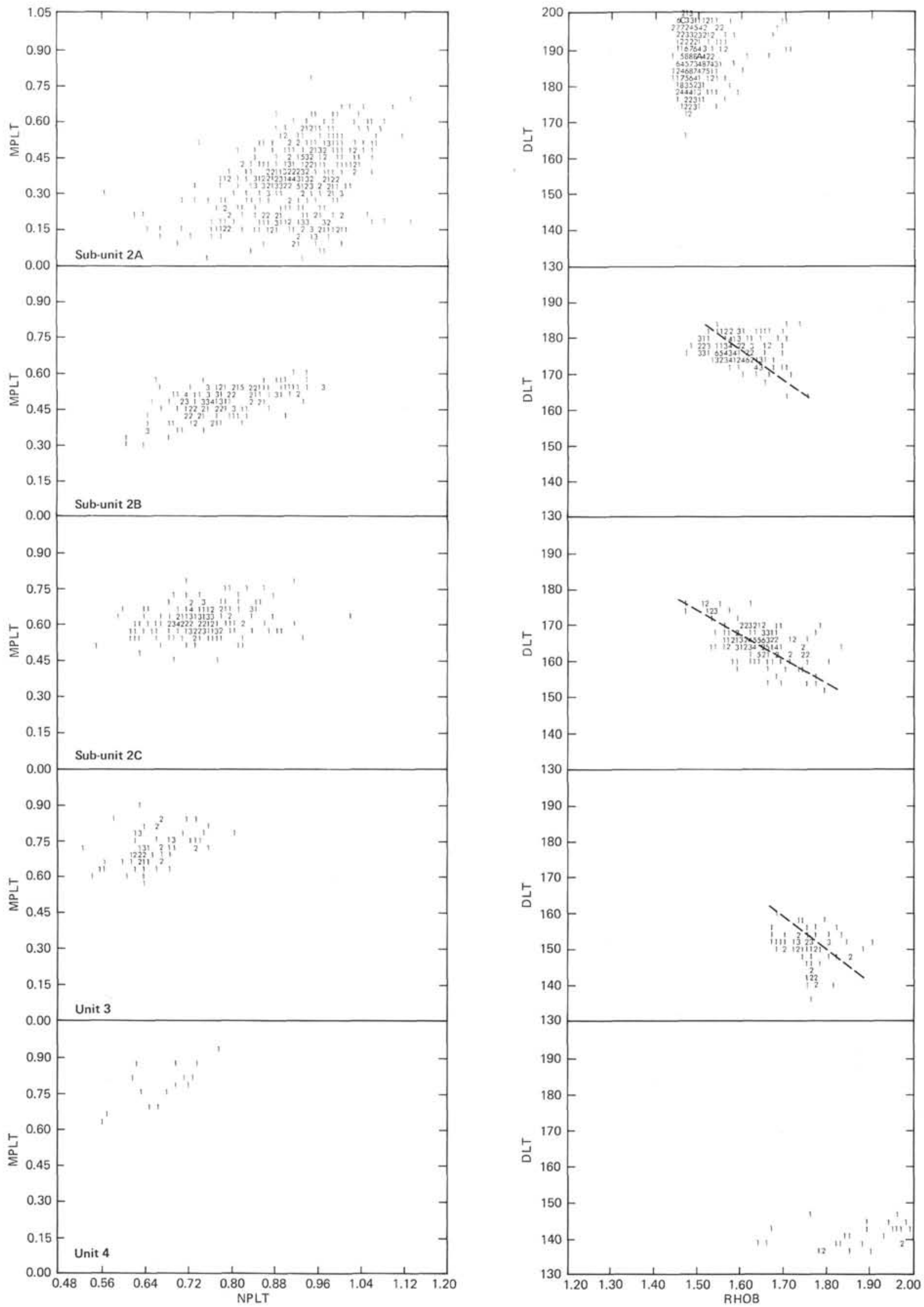

Figure 5. Cross plots of logs from Site 439. ( $M-N$ plots on right, DLT/RHOB on left.) 

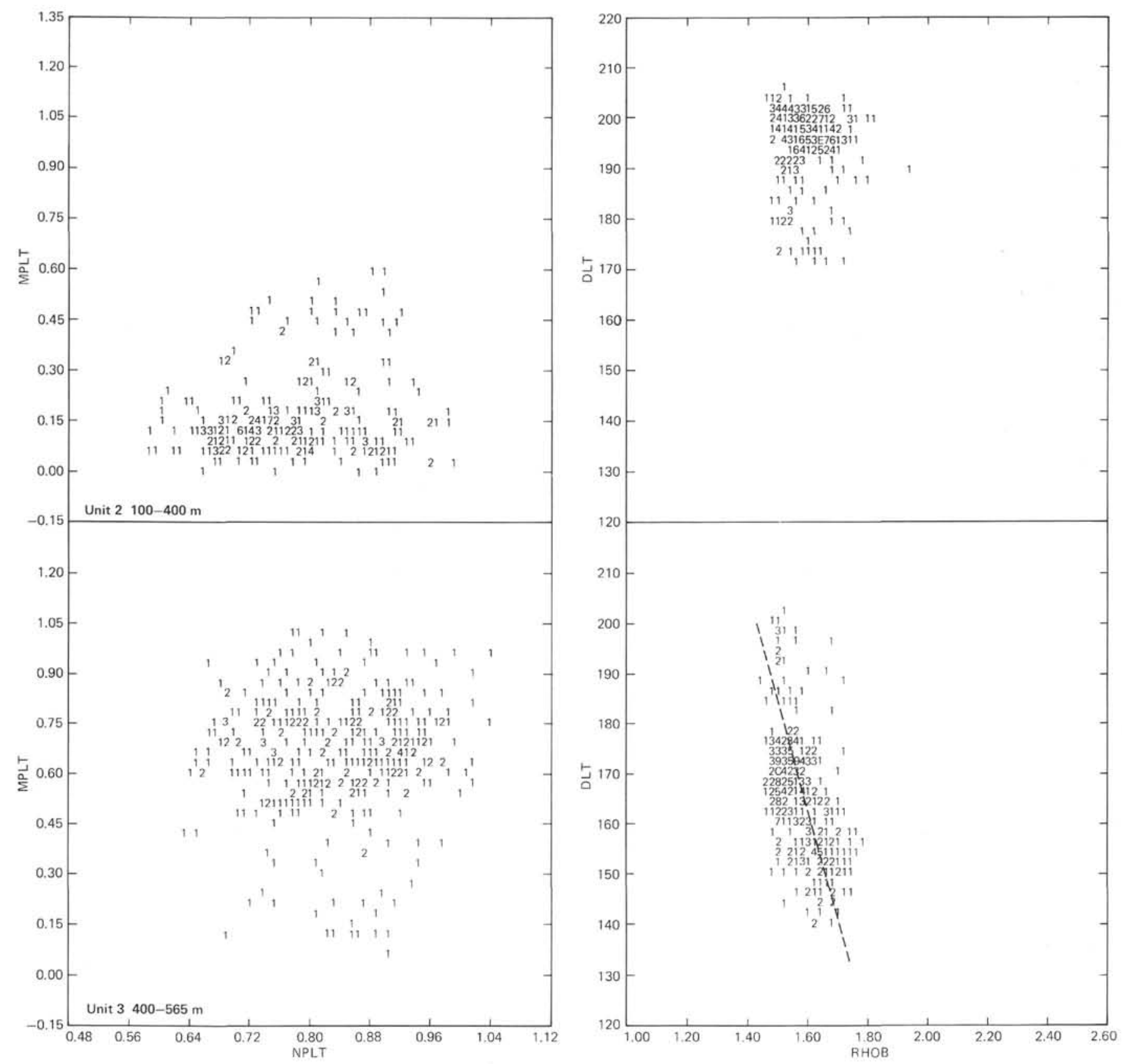

Figure 6. Cross plots of logs from Site 440. M-N plots on right, DLT/RHOB on left.

the lower cross plot (Figure 6). Since velocity increases relatively regularly with depth, the cross plot generally shows the density decrease with depth in the upper part of Unit 3. The corresponding reversal can be seen in the $\mathrm{M}-\mathrm{N}$ plot, but not as clearly.

\section{Site 441}

The single formation density-gamma ray logging run at Site 441 was all that weather conditions would allow. The log traces at 441 are amazingly similar to those at 440 in that both have the peculiar low density zone. Within the low density zone, the trace is relatively smooth and remains at an almost constant value. At Site 441 it occurs some 20 to 30 meters shallower than at 440 .
Because of scale, the low density zone is not apparent in Figure 7. However, bulk density increases from 1.55 at 100 meters to about 1.80 at 220 meters and then declines to 1.54 at 380 meters, where it remains constant to 560 meters. At the very bottom of the interval there is a sudden increase to about 1.8 .

\section{SYNTHETIC SEISMOGRAMS}

A quantitative technique by which lithology can be related to features in seismic records is through synthetic seismograms. Synthetic seismograms were derived from the sonic and formation density logs at sites where both logs were run $(438,439$, and 440$)$. To relate the synthetic seismogram to the seismic record, velocity 

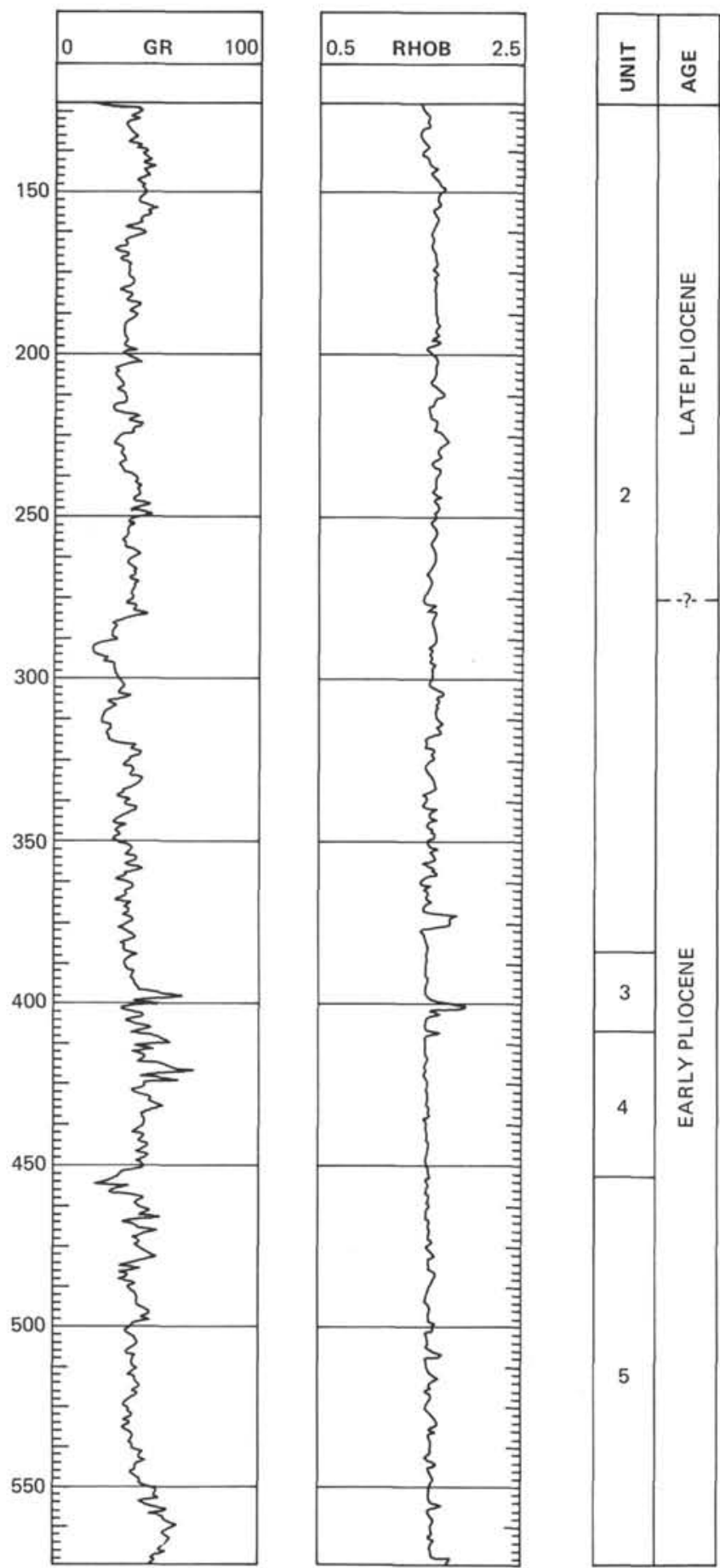

Figure 7. Formation density (RHOB) and gamma ray (GR) logs from Site 441. must be known well enough to relate core and log depths to the time along the vertical axis of the seismic record. This is not always straightforward, because, for one thing, marine seismic sources examine a large area of the ocean floor. Thus the reflection record is a composite of the effects from a wide area, whereas the logging tool measures effects in a small radius around the drill hole. Only the contrasts of rock density and sonic velocity over a broad area would be expected to correspond in both the synthetic seismogram and the seismic recordings.

The logs and synthetic seismograms are shown with time rather than depth as the vertical axis (Figures 8, 9, and 10). The time is the two-way travel time along the vertical axis of the seismic records. Time-depth equivalents were derived from sonic velocities at various depths as measured by seismic refraction, interval velocities derived from the stacking velocities in the multichannel records (see seismic records, back pocket, this volume, Pt. 1), velocity measurements (Carson and Bruns, this volume), and the downhole sonic log.

Before drilling, a general curve of seismic velocity as a function of time was constructed using interval velocity derived from the stacking velocity at two shotpoints near Sites 438 and 439 (Figure 11). At these shotpoints the reflections are near-horizontal and continuous, making the stacking velocities relatively reliable. In addition the refraction velocities were used (Murauchi, this volume). This general curve agrees well with equivalent curves from the sonic logs of Sites 438 and 439 . The log curve from Site 439 has slightly higher velocities at equivalent subsurface depths. An explanation for the rapid increase in velocity below $1 \mathrm{~s}$ at Site 439 is the increase of sand turbidites in Units 3 and 4 . The curve from the Site 440 sonic log shows an even greater increase in velocity, and this site is in 2949 meters deeper water than Site 438 .

The differences between the general (derived from seismic data) and log (derived from the 438 and 439 sonic $\log$ ) curves are an indication of the magnitude of uncertainty in depth determinations. Since imprecision is additive, the uncertainty will increase with depth. At 900 meters, the general and log derived velocities differ by about $150 \mathrm{~m} / \mathrm{s}$. At $1 \mathrm{~s}$, the general and the log curves give depths that differ by about 30 meters. These differences are of about the same scale as the seismic reflections. In the seismic records, reflections are spaced about $22 \pm 4$ meters apart.

Prominent or high amplitude reflections in the synthetic seismogram correlate well with high amplitude reflections in seismic records across Site 438 (Figure 12), particularly if the reflections are traced a few kilometers landward and out of the zone of small faults near the site. The correspondence between synthetic and recorded sequences is within $1 / 2$ phase, above reflector D (Figure 12) and within one phase below it. The logged events that produce a marked change in impedance are commonly a pronounced density event corresponding to a noisy velocity event. Perhaps the sonic log was af- 

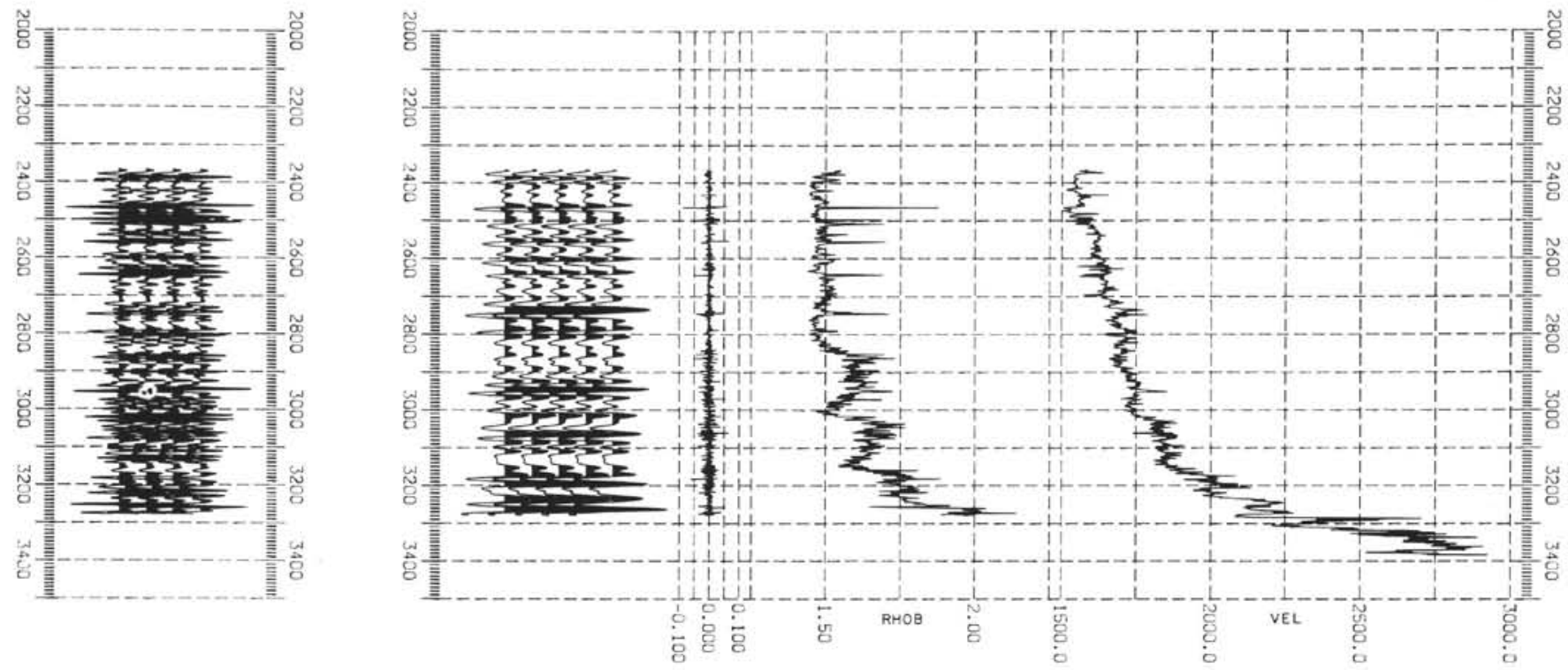

Figure 8. Synthetic seismogram, Site 438. (Vertical axis in milliseconds round trip travel time, corresponding to seismic reflection record across the site. Far right, sonic velocity trace, horizontal axis in $M / S$, then formation density trace, horizontal axis in $\mathrm{Mg} / \mathrm{M}^{3}$. At left, reflectance, horizontal axis is amplitude ratio freflection coefficient]; at far left, resulting synthetic seismogram.)
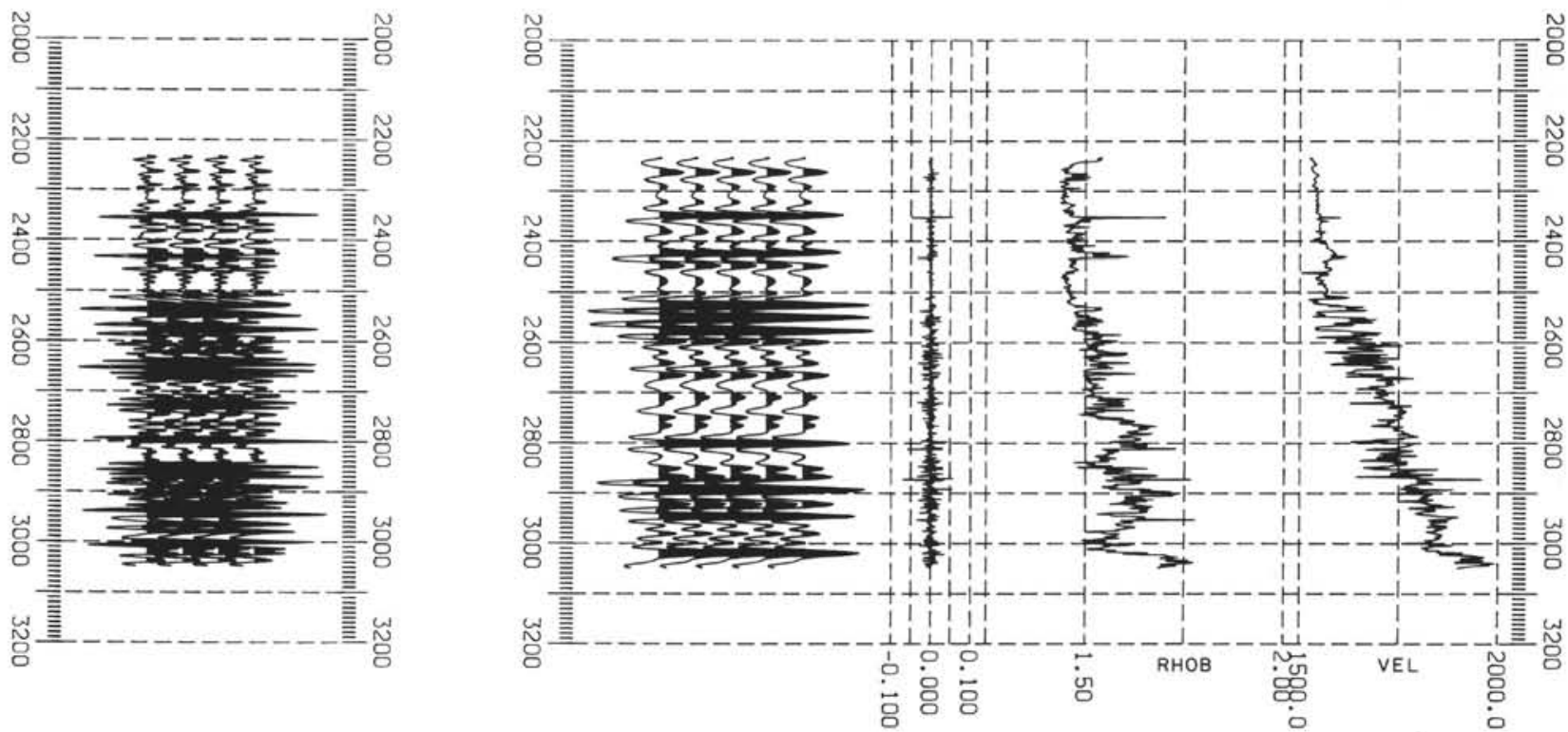

Figure 9. Synthetic seismogram, Site 439. (See Figure 8 for explanation.)

fected by hole roughness in these areas. The log features were converted from depth to time by a series of straight lines approximating the velocity with depth curve derived from the logs; this could explain some of the imprecision in matching synthetic and recorded reflections.

In the hemipelagic mud section, high amplitude reflections occur most frequently in intervals with numerous thin ash beds and associated carbonate rich or limestone horizons. Less frequently, the changes correspond to sharp variation in diatom content-for in- stance, from a diatomaceous mud to a diatom ooze. Deeper in the section (below about $450 \mathrm{~m}$ ) silicification may contribute to a high amplitude reflection. At the boundary between Sub-unit $2 \mathrm{C}$ and Unit 3, greater sand content correlates with a strong reflection.

The log correlation described in the site chapter for Sites 438 and 439 between the two was done aboard the Challenger, using field prints of the logs. Our correlation, using corrected logs, the synthetic seismograms, and reflection traces in the seismic records (Figure 12), differs by about 20 milliseconds (approximately $20 \mathrm{~m}$ 

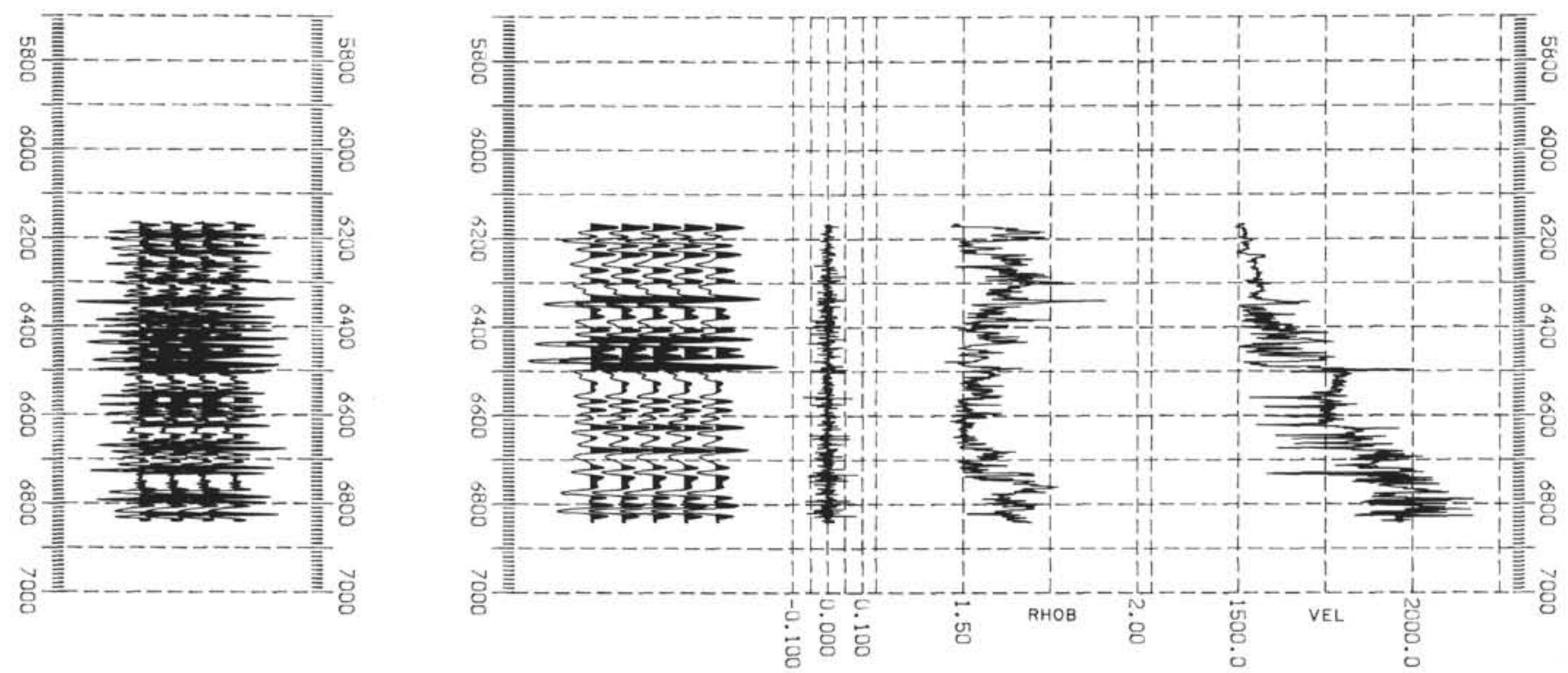

Figure 10. Synthetic seismogram, Site 440. (See Figure 8 for explanation.)

shallower at Site 439) for reflections above D. We have no explanation for this other than a depth-to-time conversion error during the synthetic seismogram process.

Reflections X, A, and B (Figure 12) have a characteristic pattern in both sets of logs and can also be traced in the seismic records from one site to the other. Reflection $\mathrm{D}$, one of the strongest in the observed seismic record, does not correspond in a straightforward way to the logs, the synthetic seismograms, or the lithology. Our interpretation of its position at Site 439 is heavily influenced by the tracing of the reflection from one site to the other.

At Site 440 the synthetic seismogram and seismic reflection record cannot be interpreted straightforwardly (Figure 13). First, the seismic record does not record amplitude information well, probably because of fracturing or seismic processing. Second, the logs were run under adverse weather conditions and are relatively noisier than other logs (compare the 439 and 440 sonic traces). Thus, many of the short wavelength $(10 \mathrm{~m}$ or less) events are probably noise, particularly in intervals where the hole was rough. Rough and washed-out hole intervals commonly correspond to highly fractured intervals. Third, the section is lithologically very monotonous, consisting of claystone with small variation in diatoms and volcanic ash and pumice fragments. Where the ash content is greater by 10 per cent or more, the formation density shows a small increase over a 10- to 50 -meter-thick interval which corresponds to a low frequency reflection in the synthetic seismogram. Such low frequency reflections are seen in the seismic record (cf. $6300-6500 \mathrm{~ms}$ ).

\section{SUMMARY AND CONCLUSIONS}

Despite severe shipboard operational problems, especially at Sites 440 and 441 , studying the log traces produced a great deal of confidence in their general validity. When the logs are compared with laboratory mea- surements, lithology, and seismic records, and when an intertrace comparison is made, that general validity becomes apparent. The precision across an interval of a few meters is good, and uncertainty increases with succeeding smaller intervals. The precision of small features $(1-3 \mathrm{~m})$ is difficult to establish. Although some 2-to 5-meter excursions of the traces correspond well with lithologic and seismic features, the uncertainty in the precision of other features at this scale is problematical. Thus further detailed interpretation of lithology based on the logs must be done with considerable care and caution, particularly at Sites 440 and 441 , where unknown environmental effects are superimposed on the traces.

The evidence for secondary porosity is derived principally from the unusual decrease with depth in the formation density log supported by the sonic $\log$. The trend in $\mathrm{M}-\mathrm{N}$ plots derived from these logs, the derivative porosity curves, and cycle-skipping in the sonic log support and emphasize the logging evidence. The sonic signal is attenuated in a highly fractured medium and could cause cycle skip. Because the core was not especially gassy in the interval in question, gas can be ruled out as a cause. An increase in the porosity derived from the formation density log at Site 440 is highly indicative of secondary porosity, and the trend of successive $\mathrm{M}-\mathrm{N}$ plots for the logs from Site 440 is consistent with secondary porosity. The case for fracture porosity is developed more fully elsewhere (Arthur et al., this volume).

There is a good correspondence between log traces, lithology, and the seismic records. The logs are a set of data at an intermediate scale between core information and seismic records that aid in correlating lithology with seismic data. The use of synthetic seismograms has made this correlation of different data far less subjective than is usual in Glomar Challenger studies. The most frequent correspondence between strong reflections and core lithology is at ash beds, then at lime-rich 


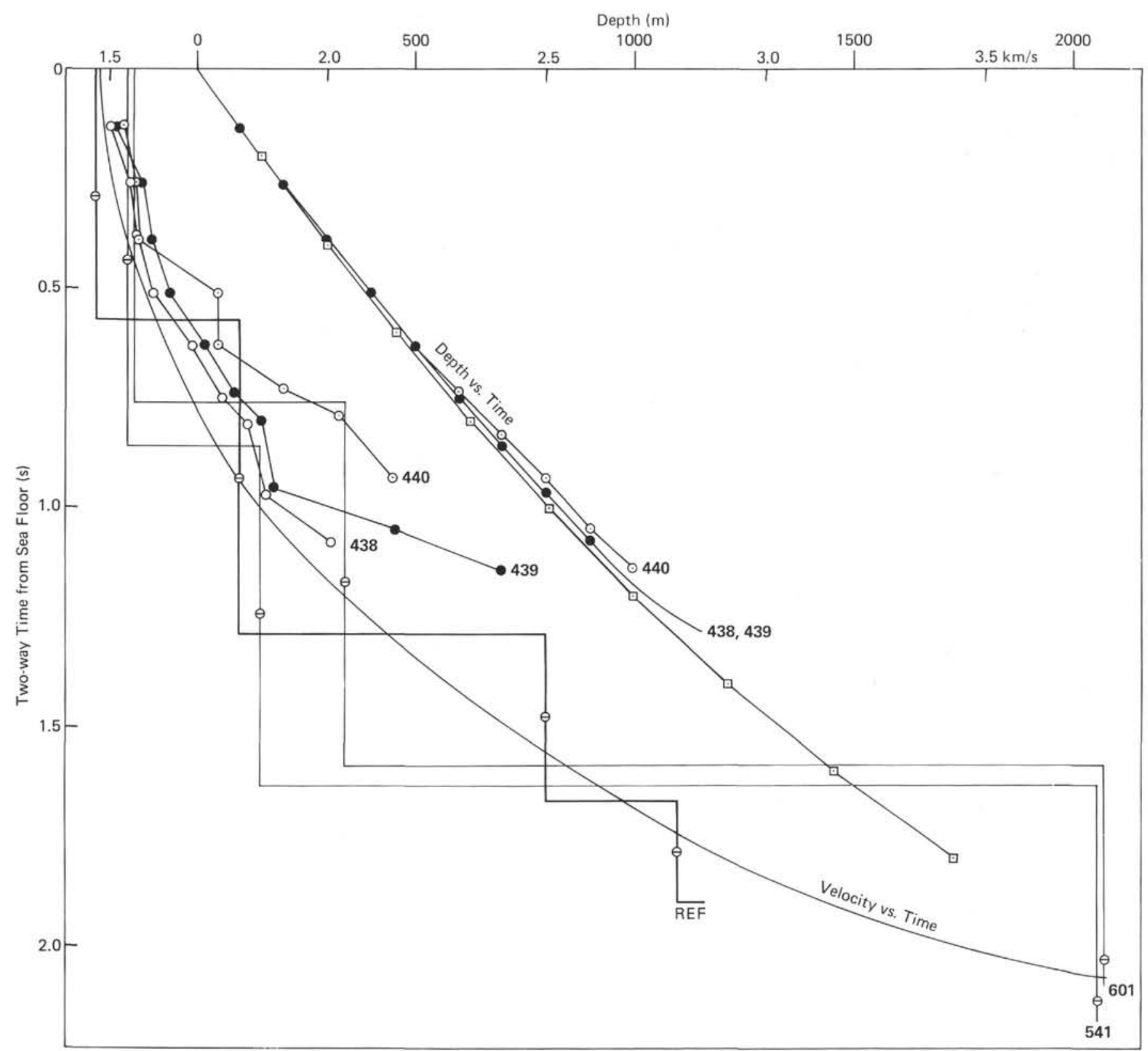

Figure 11. Summary of velocity analyses. (Stepped trace REF is from refraction measurements; stepped traces 541 and 601 are summations of interval velocities from stacking velocities at those shotpoints; and traces with site numbers are from the sonic logs. The corresponding depth-time traces are on the right.)

or limestone beds (Figure 14). In the section penetrated, these beds are usually too thin to cause a change in acoustic impedance and relativity by themselves, but when they are sufficiently numerous and properly spaced, they are capable of causing greater than average reflectance. The lateral continuity of reflections is consistent with an airfall origin of the ash layers and with the development of the thin limestone beds associated with the greater permeability of the ash relative to the mudstone. The variation in diatom and sand content corresponds less frequently with change in reflectivity.
The basic conclusions from our study are as follows:

1) The formation density and sonic log traces give precise values over intervals about a few meters long. In shorter intervals the precision of a particular log must be judged on the basis of log character, a comparison between all log traces and lithology, and a comparison with the physical properties data.

2) The consistency between laboratory measurements of physical properties and the log values indicate a general correspondence between in situ and laboratory values (also discussed in Carson and Bruns, this volume). 

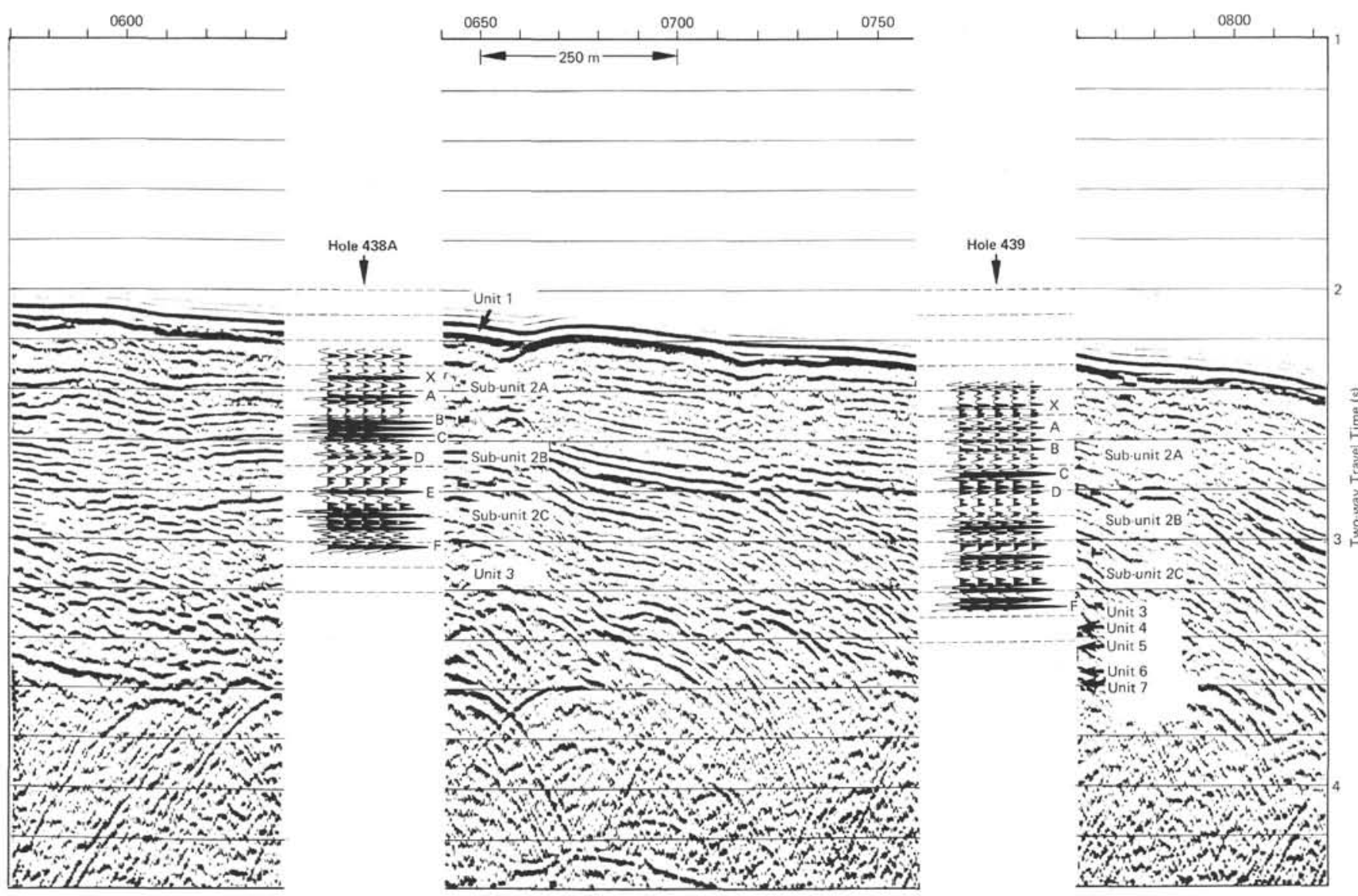

Figure 12. Seismic record and superimposed synthetic seismogram, Sites 438 and 439.
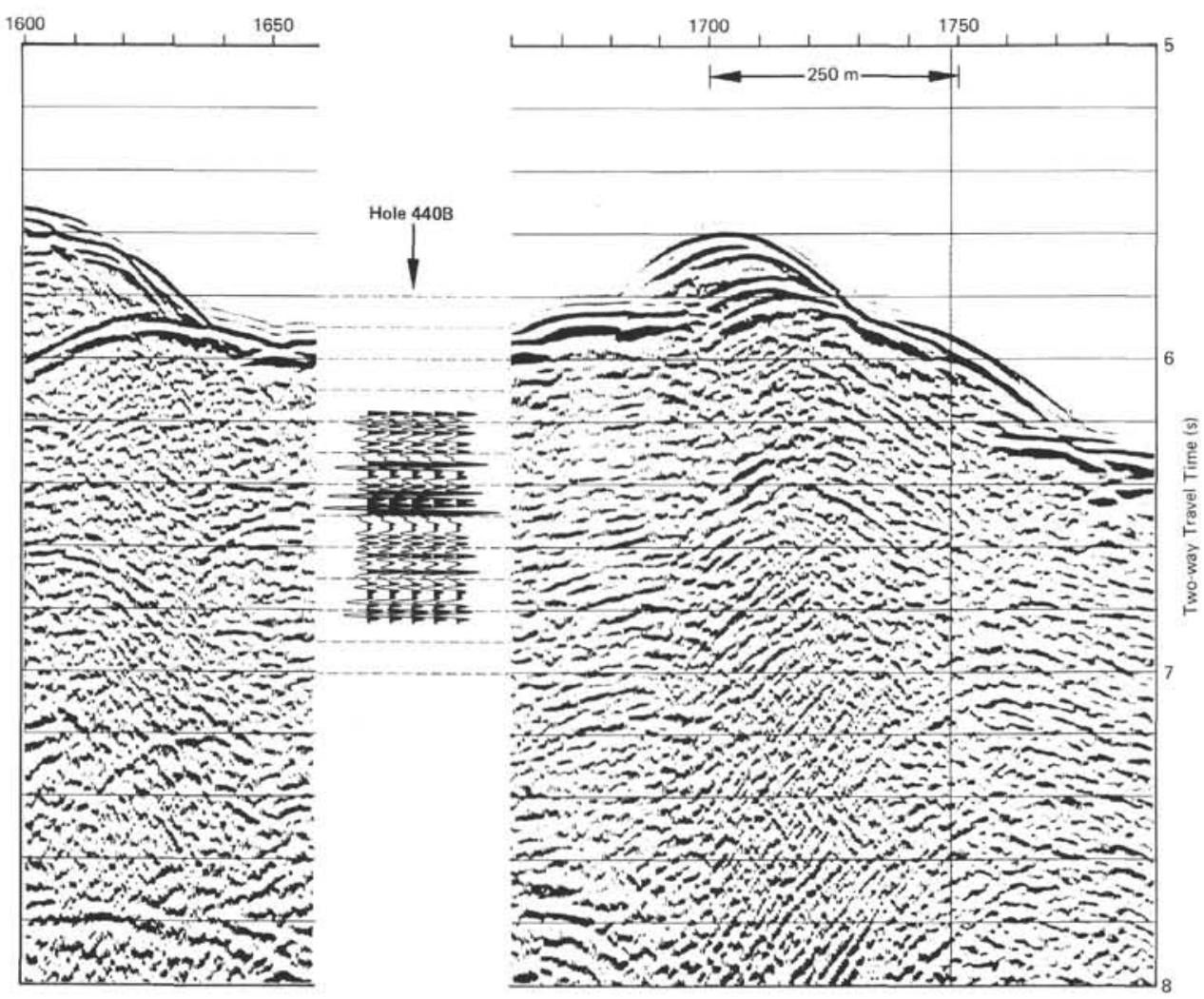

Figure 13. Seismic record and superimposed synthetic seismogram, Site 440. 


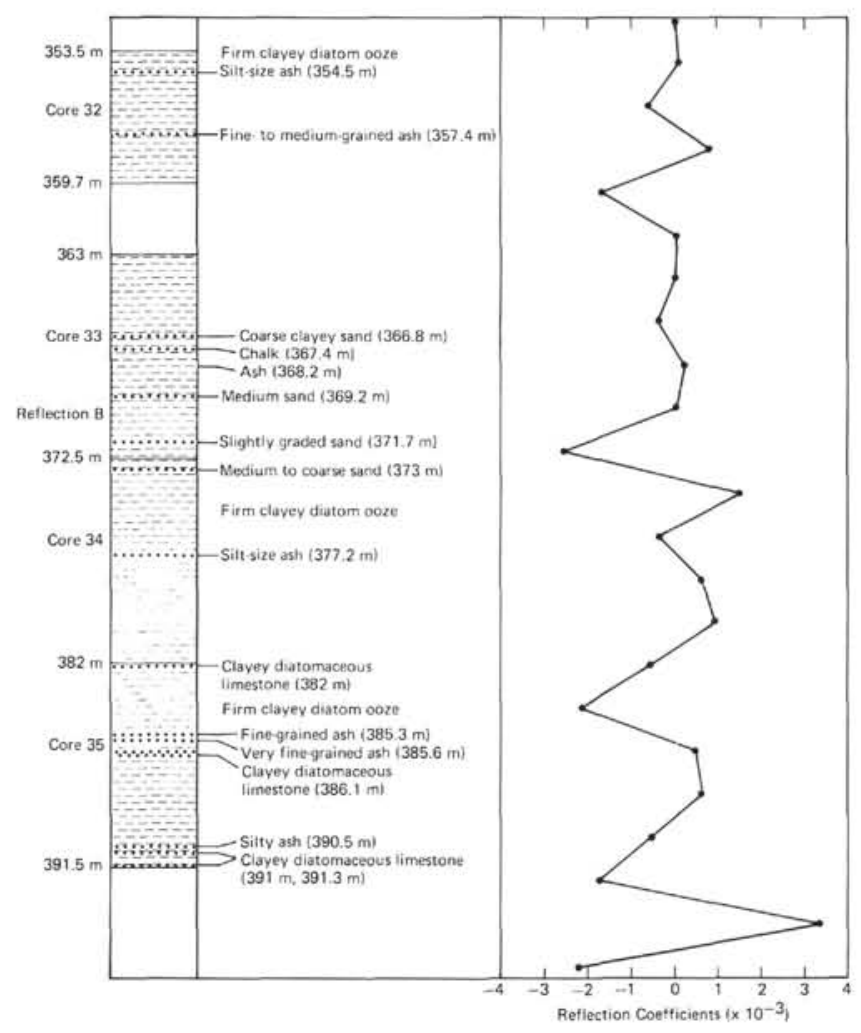

Figure 14. Correspondence between strong reflections, reflection coefficients, and core lithology, Site 438.

3) Most intervals not recovered in coring have the same character in the logs as the recovered intervals. Thus no unusual lithologies appear to have been missed during coring. The most consistent correlation is between poor core recovery at highly fractured intervals and noisy $\log$ traces, particularly the sonic trace at Site 440 .

4) The decrease with depth in formation density log values at Sites 440 and 441 , in reference to those at 438 and 439 , are consistent with the development of secondary porosity and overpressured zones. The sonic trace shows some similar decreases at Site 440 , but the interpretation is not as straightforward.

5) In the rather monotonous mudstone section, sequences of thin volcanic ash beds and related limestones and obvious lithological change appear to form the most prominent horizons in seismic records. The timeconsistent nature of airfall ash deposits lends support for the assumption that prominent seismic reflections are also time-consistent.

This study has made clear to us the need for logs with proper environmental measurements in relating lithology to seismic data in the DSDP program.

\section{ACKNOWLEDGMENTS}

We thank Bob Brune and Roy Hyndman for reviewing the manuscript. We also thank Dieter Bartsch of the Singapore office of Schlumberger who served on board.

\section{REFERENCES}

Wyllie, M. R. J., Gregory, A. R., and Gardner, G. H. F., 1956. Elastic wave velocities in heterogeneous and porous media. Geophysics, 21 (No. 1), 41-70.

1958. An experimental investigation of factors affecting elastic wave velocities in porous media. Geophysics, 23 (No. 3), 459-493.

GENERAL BIBLIOGRAPHY FOR LOGGING

Log Interpretation. Principles (Vol. 1): New York (Schlumberger Limited). 1972.

Log Interpretation Charts: New York (Schlumberger Limited). 1977. 